\section{Spread excellence across Europe}

In February, we expect the results of the first call for proposals for the 'Teaming of Excellence' strategy across the European Research Area. It is to be hoped that we have learned from previous mistakes.

Attempts by the European Union's Framework Programmes for Research and Technological Development to close gaps in research excellence across the region have been spectacularly unsuccessful. In my view, this failure is a result of excessive bureaucracy and a proposalevaluation system that was seemingly based neither on merit nor on evidence. The misguided focus on upgrading existing research institutions - rather than on creating state-of-the-art structures that are free of the conventional organizational drag on performance - was also a waste of money.

The Horizon 2020 plan for Teaming of Excellence heralds a new approach. It supports the creation of centres of excellence in member states that are lagging behind in research, set up as joint ventures with excellent partners from other member states. It is to be hoped that the commitment to forming these new centres will take priority under the evaluation criteria, so that this time we can genuinely close structural disparities in science and "spread excellence".

Maciej Żylicz Foundation for Polish Science, Warsaw, Poland. maciej.zylicz@fnp.org.pl

\section{Indirect costs: cash is no gravy train}

Aspects of your report on US federal funding of direct research costs and the indirect costs of facilities and administration are misleading (Nature 515, 326-329; 2014).

Contrary to your claim, no one is benefiting from federal largesse. Rather, the
US government is partially reimbursing research universities for audit-verified indirect costs that they have already incurred.

Negotiated and actual recovery rates for indirect costs vary across the academic community because federal research funding is merit-based, not a welfare programme. Moreover, institutions may be private or public, urban or rural, with different structures, sizes, missions and financial anatomies.

The biomedical sciences depend on powerful technologies that require special housing, considerable energy consumption, and maintenance. Administration is being bloated by federal regulations, many of which dictate how scientists conduct and disseminate their research. It is therefore all the more remarkable that the share of extramural research spending on indirect costs by the US National Institutes of Health (NIH) has been stable at around 30\% for several decades.

Our respected system of federal funding needs to be accurately and fairly presented in this era of US budget distress and political gridlock, especially given that the NIH budget has lost $25 \%$ of its purchasing power in the past decade while grant applications have more than doubled.

David Korn Massachusetts General Hospital and Harvard Medical School, Boston, USA. david_korn@harvard.edu

\section{Indirect costs: the reimbursement gap}

The gap between the indirect costs of research reimbursed to US universities and the actual costs is wider than you suggest (Nature 515, 326-329; 2014). If we are to "keep the lights on" to do our research, we must reduce this gap.

For example, the University of South Florida's reimbursed indirect cost rate negotiated from federal funding was $49 \%$ of total direct research expenditure in 2013, whereas the actual rate was more than $54 \%$; the recovery of indirect costs is even lower for many universities after all sources of external research funding are taken into account (K. A. Holbrook and P. R. Sanberg Technol. Innov. 15, 269-280; 2013).

Demands on institutional support for core facilities and for more-flexible funding schemes are likely to increase as university research becomes more transdisciplinary (see go.nature. com/uwu62q). Reducing the administrative burden by streamlining processes will help in meeting these demands.

Paul R. Sanberg, Judy Genshaft, Sudeep Sarkar University of South Florida, Tampa, Florida, USA. psanberg@usf.edu

\section{Disaster mapping by citizens is limited}

Growing numbers of citizen scientists are joining the professional community to map structural damage caused by natural disasters such as Typhoon Haiyan, which struck the Philippines in 2013 (see Nature 515, 321; 2014). However, stakeholders need to recognize some crucial limitations of crowdsourced contributions.

Citizen scientists are invaluable for mapping roads accurately and for picking out local points of interest. But when it comes to analysing structural damage, even high-resolution satellite data are inadequate. For example, fine-resolution aerial imagery revealed that damage after the 2010 Haiti earthquake was ten times worse than originally concluded by mapping volunteers. Moreover, vertical data cannot provide a comprehensive picture, particularly of partial damage (see N. Kerle and R. R. Hoffman Nat. Hazards Earth Syst. Sci. 13, 97-113; 2013).

Furthermore, volunteers receive only minimal instruction.
They are not trained to map structural damage, which relies on image proxies such as shadows and debris, nor do organizers of the mapping systems provide corrective feedback for improving mapping accuracy.

Coordination with professional organizations on standards and terminology must also be improved if the needs of disasterresponse stakeholders are to be met.

Norman Kerle University of Twente, Enschede, the Netherlands. n.kerle@utwente.nl

\section{Bold alliances aid translational work}

We propose that translational research needs to venture out of its comfort zone and become more interdisciplinary. Physicians, pharmacists, statisticians, computational biologists, social scientists and others from academia, health care and industry should be working hand in hand.

Our interdisciplinary translational research group (see go.nature.com/sgdrga), part of an association of research-intensive European institutions in the life sciences called EU-LIFE, aims to foster a continuous cycle from basic to clinical research and back.

To ensure the success of interdisciplinary translationalresearch programmes, we suggest that each partner should verse the next generation of basic and clinical scientists in the programme's aims; that intellectual-property rights need to be formally stated and managed; that clinicians' research time should be protected; and that funding agencies should create sustainable funding opportunities for basic research that are informed by unmet medical needs.

Janine T. Erler ${ }^{\star}$ University of Copenhagen, Denmark. janine.erler@bric.ku.dk ${ }^{*}$ On behalf of 4 correspondents (see go.nature.com/ad21lk for full list). 